\title{
CERÁMICA PROCEDENTE DEL YACIMIENTO DE PORTA DE ARCOS (Rodeiro.- Pontevedra)
}

\author{
Por \\ M LUISA ÁLVAREZ TORRÓN
}

\section{INTRODUCCIÓN}

El yacimiento a tratar está situado en el municipio de Rodeiro (Pontevedra), en el límite de la parroquia de San Xoán de Camba con la de Santiago de Fafián, cerca de Lalín, en el lugar conocido como «Porta de Arcos» o «Leira das Penas».

Se trata de una villa romana situada en un valle, cercano a la vía romana Braga-Lugo (vía 19), que sale por la vaguada de A Portela. Un dato importante es la existencia de más localidades denominadas «villa» con presencia de cerámica romana en superficie ${ }^{1}$.

Hasta 1973 fueron descubiertas importantes construcciones: una cocina, un fragmento de mosaico de fines del s. III o principios del s. IV, fragmentos de capiteles, semicolumnas, una canaleta de conducción de aguas hecha con «tegulas», un bronce de Antonino (año 161-162), tres pequeños bronces ilegibles, uno de Galieno (año 267). Apareció también una construcción independiente a la villa (dos muros), coetánea del mosaico mencionado anteriormente.

' GÓNZALEZALÉN, D.: Gran Enciclopedia Gallega, vol. 11, Santiago de Compostela, 1974, 69 .

"CUADERNOS DE ESTUdIOS GALLEGOS", Tomo XLVII, Fascículo 112, Santiago 2000. 
La villa romana de Rodeiro, según datos de 1973, se podría datar entre principios del s. II y finales del s. III o principios del s. IV 2 .

Debe precisarse que en este artículo se tratará únicamente del material cerámico de dicho yacimiento que se halla depositado en el Instituto «Padre Sarmiento» de Estudios Gallegos, ya que la mayor parte del material resultante de las diferentes campañas de excavación se encuentra en el Museo de Pontevedra.

Se trata, aproximadamente, de 1200 piezas de cerámica que comprenden desde cerámica común (en su mayoría de cocina) hasta «terra sigillata», lucernas, fusaiolas, etc., resultado de tres campañas arqueológicas llevadas a cabo en los años 1971, 1972 y 1973 por D. García Alén.

El número que acompaña a alguna pieza en este artículo, corresponde a la numeración del inventario general existente en el Instituto «Padre Sarmiento», realizado en el año 1996.

\section{ANÁLISIS TIPOLÓGICO}

El conjunto del material cerámico se clasificará, para su análisis, según sus formas y clases; es decir, se dividirá en: cerámica común y «terra sigillata». Dentro de la primera, a su vez, se diferenciará según se trate de bordes, bases, asas, fragmentos del cuerpo o amorfos, u otros materiales.

\section{1) Bordes:}

a) Tipos:

(Pieza 1) Curvo convexo con labio recto y perfil sinuoso (ver foto 1); curvo convexo con labio redondeado; alguna pieza con paredes finas. Curvo cóncavo con labio redondeado, redondeado engrosado hacia el interior o engrosado hacia ambos lados; curvo convexo exvasado; curvado abierto y perfil del cuerpo globular; ligeramente curvo abierto y labio horizontal exvasado; curvo cóncavo exvasado; curvo convexo cerrado, con ligeras inflexiones (apenas visibles) a medio camino entre la técnica indígena o prerromana y la romana, como la 525; curvo, con labio apunta-

\footnotetext{
${ }^{2}$ Yacimiento de «Porta de Arcos» (Rodeiro.- Pontevedra). Villa romana, Museo de Pontevedra, vol. 1973, 65-68.
}

"CUADERNOS DE ESTUdios GAlLEGOS", Tomo XLVII, Fascículo 112, Santiago 2000. 
do y cuello recto; curvo convexo con terminación curvo cóncava y labio apuntado.

Oblícuo abierto con labio redondeado; igual que el tipo anterior pero con grandes molduras incisas en la parte interior del borde; oblícuo abierto con cuello cóncavo angular y labio redondeado; oblícuo con cuello curvo cóncavo; oblícuo abierto con labio horizontal; oblìcuo con labio engrosado hacia el exterior o interior; oblícuo ligeramente curvado con labio recto horizontal engrosado hacia el exterior.

Recto horizontal; recto con labio redondeado (con cuello curvo cóncavo en alguna pieza); pared muy fina, borde recto horizontal y labio redondeado; recto de labio oblícuo; recto horizontal con labio horizontal engrosado hacia el exterior. (Pieza 21) Borde facetado, lo cual indica un tipo de cerámica más antigua, que no domina aún la técnica romana.

En cuanto a las formas, se trata de ollas de cocina, cuencos, predominando los tamaños mediano-grandes. (Pieza 52/170) Levemente facetado, lo que indica una etapa de camino hacia la técnica romana, aunque no se haya perfeccionado todavía. El labio es recto, levemente hundido en el centro. Se trata de una olla de gran tamaño; la pieza 512 presenta un borde de dos facetas con labio recto horizontal; también hay bordes facetados (una faceta) con labio redondeado, facetado con labio apuntado; a veces presentan pequeñas molduras en el interior que servirían de apoyo a una tapadera; (piezas 167, 2295,2302, 2307, 2311, 2617) paredes gruesas y tamaño grande; borde cóncavo y, a continuación, oblícuo abierto con labio redondeado.

b) Color:

Gris (en todas sus tonalidades, del más claro al más oscuro); gris con pigmento anaranjado; gris parduzco; algunas piezas, como las 7 y 149 , con engobe casi negro en toda la superficie; otras con engobe anaranjado o pardo; gris en el interior y, hacia la superficie, anaranjado oscuro. Barniz gris.

Anaranjado en diferentes tonalidades; anaranjado con engobe rojo anaranjado en la superficie; con pigmento gris oscuro en la parte exterior; con engobe rojo oscuro en el interior y gris oscuro en el exterior; gris en el interior y ocre anaranjado hacia la superficie; igual con engobe rojo en la superficie interior.

"CUADERNOS DE ESTUDIOS GALLEGOS", Tomo XLVII, Fascículo 112, Santiago 2000. 
Pardo (del más claro al más oscuro); con barniz gris oscuro o negro; pardo anaranjado; con engobe rojo anaranjado en superficie; pardo grisáceo; pardo con zona anaranjada (cocción irregular).

Ocre; (pieza 214) ocre con mancha rojiza en la superficie (cocción irregular); ocre anaranjado.

Rojo con engobe rojo en la superficie interior, rebasando el borde.

c) Desgrasantes:

Graníticos, con abundante mica en la mayoría. El tamaño de los desgrasantes es grande en la mayoría de las piezas, por ejemplo 1, 2295-2296, 2460. En alguna pieza, como la 2297, son micáceos aunque predominan los graníticos.

\section{d) Terminación:}

Espatulada y, en el exterior, ligeramente bruñida; afinada; bruñida; grosera; afinada en el exterior y grosera en el interior; espatulada y bruñida; barnizada o pigmentada y escobillada; bruñida en el exterior y afinada en el interior; barnizada y bruñida; afinada y engobada en la superficie interior; espatulada en el exterior y engobada en el interior; escobillada; espatulada.

e) Cocción:

Reductora y oxidante, con un porcentaje similar o un leve predominio de la primera. En las piezas 52/170 y 2314 , reductora primero y, después, oxidante.

\section{f) Decoración:}

Molduras horizontales excisas y decoración de retícula bruñida en la panza, como en la pieza 1; molduras horizontales excisas, líneas horizontales incisas acanaladas y bruñidas, arcos de medio punto puntillados (decoraciones que proceden, en su mayoría, de la tradición prerromana o indígena); líneas horizontales bruñidas; líneas verticales semibruñidas.

g) Observaciones:

En la decoración de la pieza 1 subsiste la tradición prerromana aunque su técnica es más evolucionada. Se ve en esta pieza una cohesión de am- 
bas culturas: la romana (en la factura) y la prerromana (en la decoración). Se trata de una pieza de cocina (olla) como lo demuestran las señales de exposición al fuego.

La pieza 52/170 parece tratarse de un recipiente de cocina dedicado a almacenaje o preparación de alimentos ya que no presenta señales de exposición al fuego. Su factura es muy tosca (al igual que la pieza 2313).

En la mayoría de las piezas aparecen huellas de una exposición al fuego lo que, junto a la aparición en algunas de moldura interior para apoyo de tapadera, nos demuestra que se trata de cerámica de cocina.

Alguna presenta un ennegrecimiento en la pasta debido a una carbonización posterior a su rotura; otras sólo presentan ennegrecimiento en su interior. Cuando no se utiliza para cocción, es para guardar o preparar alimentos.

Alguna pieza, como las 2114 y 2303, presentan señales de fabricación a torno, dato que indica el conocimiento de la técnica romana, aunque conviviendo con la prerromana.

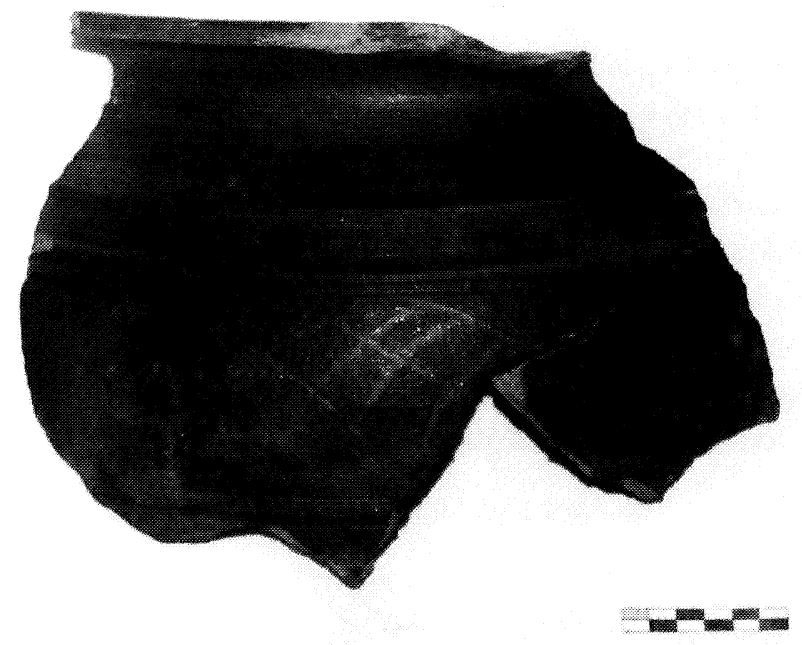

Foto 1.- Pieza 1.

"CUADERNOS DE ESTUDIOS GALLEGOS", Tomo XLVII, Fascículo 112, Santiago 2000. 


\section{2) Bases:}

a) Tipos:

Pieza 5: Base con «cartela» rectangular en la parte interior de la pieza (GB), fragmentada. Este sello indica el taller o fabricante del que procede. Es una marca producida antes de la cocción: «signacula». Quizás sea un nombre de persona abreviado (ver foto 2 ).

Pared oblícua abierta, fondo plano y reborde perimetral recto vertical, curvo convexo o curvo cóncavo; pared curvo cóncava (algunas piezas con perfil globular), como la pieza 76, cuenco de forma semiesférica con arranque de asa; reborde perimetral oblícuo, curvo cóncavo; fondo convexo, formando una carena en la unión de fondo y pared; fondo ligeramente curvo convexo; pared oblícua y fondo curvo cóncavo con reborde perimetral curvo cóncavo; fondo curvo cóncavo y reborde perimetral recto vertical.

Hay piezas, como la 163, con paredes de gran grosor.

\section{b) Color:}

Gris muy claro con engobe rojo anaranjado en la superficie; gris en todas sus tonalidades; con engobe anaranjado en el interior y pigmento gris oscuro en superficie.

Anaranjado, en ocasiones muy claro, casi ocre.

Pardo anaranjado; pardo, desde el oscuro hasta el más claro; con barniz negro en la superficie interior (pieza 264); con pigmento gris o con barniz negro en superficie; con pigmento anaranjado en el exterior; pardo oscuro ennegrecido por el fuego y pardo anaranjado en la superficie; pardo claro con barniz negro en superficie; pardo rojizo; pardo con engobe rojo oscuro en toda la superficie; pardo grisáceo; la pieza 2249 presenta ennegrecimiento en toda la pasta por efecto del fuego (quizás fue hallada en un nivel de incendio).

(Pieza 222) Gris y anaranjado (cocción irregular).

Ocre, a veces muy claro.

Rojo anaranjado con engobe rojo oscuro en la superficie interior; mitad interior anaranjada y exterior ocre muy claro.

\section{c) Desgrasantes:}

Graníticos con abundante mica, en la mayoría de las piezas. En algunas, como en la 5, apenas son visibles; en otras, los desgrasantes son muy gruesos, como en las 134, 2462, 2608; y, en otras, son micáceos. 


\section{d) Terminación:}

Engobada, espatulada y bruñida en la superficie exterior; espatulada y bruñida en la superficie exterior, como la pieza 5; afinada; espatulada; bruñida (algunas sólo en la superficie exterior); algunas piezas con barniz negro; bruñida con espatulado en la superficie exterior; pigmentada; bruñida en la superficie interior y barnizada por toda la superficie; bruñida en el interior y afinada en el exterior con pigmento por toda la superficie; grosera; la pieza 2326 presenta esgrafiado en la superficie exterior del fondo.

\section{e) Cocción:}

Reductora y oxidante (con predominio de la primera); ambas coinciden en algunas piezas.

\section{f) Decoración:}

Moldura horizontal excisa; la pieza 83 muestra una leve línea horizontal incisa marcando el límite entre el fondo y el cuerpo de la misma (se repite en alguna pieza más).

\section{g) Observaciones:}

Señales de exposición al fuego y mal estado de conservación en la mayoría de las piezas; se trata de recipientes de cocina como se observa en su ennegrecimiento por el fuego (cuencos, fuentes). Los recipientes que no presentan estas características podrían ser de mesa o cocina, entendiendo este último término con otras funciones diferentes a la de cocción de alimentos, es decir, para guardarlos o prepararlos.

Hay piezas a torno, como las 2104, 2107, 2323, 2327, 2333-2335, y a torno lento, probablemente, como la 2110.

Las piezas 2189 y 2190 quizá sean platos o fuentes; la 2190 puede ser una imitación de los rojo pompeyanos típicamente romanos.

Las piezas 2213 y 2322 sólo presenta señales de exposición al fuego en el interior y la 2215 huellas de algún instrumento en la superficie interior del fondo.Algunos recipientes son de gran tamaño y paredes gruesas, como se deduce de las piezas 2322 y 2608. 

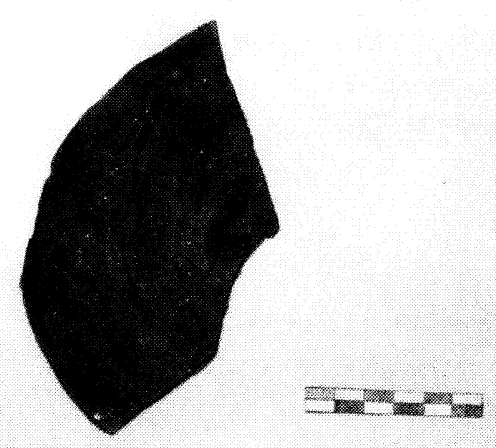

Foto 2.- Pieza 5.

3) Asas:

a) Tipos:

Aplanada, de sección ovalada, de cinta, con sección rectangular (leve depresión central en alguna), elevada o no de sección aplanada, sección cuadrangular; de cinta con sección rectangular; sección aplanada con depresión central en la superficie exterior.

\section{b) Color:}

Gris claro, alguna con engobe pardo anaranjado en la superficie; gris en el interior y, hacia la superficie, ocre anaranjado como en la pieza 52/ 170; gris en todos sus tonos; gris con pigmento pardo o pardo rojizo en superficie.

Ocre; ocre con pigmento gris oscuro en superficie; ocre anaranjado.

Anaranjado; anaranjado con pigmento parduzco en superficie.

Pardo en diferentes tonos; pardo rojizo.

c) Desgrasantes:

Graníticos (de diferentes tamaños) con abundante mica; algunos micáceos. En las piezas 52/170 y 2291 son gruesos.

"CUADERNOS DE ESTUDIOS GALLEGOS", Tomo XLVII, Fascículo 112, Santiago 2000. 
d) Terminación:

Espatulada; afinada en el exterior y grosera en el interior; grosera, bruñida, pigmentada, afinada.

e) Cocción:

Reductora y oxidante (predomina la segunda); en la pieza 52/170 la cocción es reductora primero y, después, oxidante.

f) Decoración:

Líneas horizontales incisas, retícula bruñida; la pieza 52/170 presenta digitaciones en sus extremos (ver foto 3); en la pieza 2286, dos bandas incisas, en la superficie exterior, que recorren el asa.

\section{g) Observaciones:}

Señales de exposición al fuego en su mayoría. Algunas fabricadas a torno, lo que demuestra la convivencia de ambas culturas. La 52/170 es de factura muy tosca.

h) Medidas:

$($ Pieza 2284) Anchura (en el arranque $)=4.2 \mathrm{~cm}$.; (en el centro $)=2.6$ $\mathrm{cm}$.; grosor $=0.9 \mathrm{~cm}$.

(2285) Anchura $=2.6 \mathrm{~cm}$.; grosor $=1.3-1.9 \mathrm{~cm}$. (de la parte menos gruesa a la más gruesa)

(2286) Anchura $=1.8 \mathrm{~cm}$; grosor $=0.7 \mathrm{~cm}$.

(2287) Anchura $=2.1 \mathrm{~cm}$; grosor $=1.5 \mathrm{~cm}$.

(2289) Anchura $=2.4-3.2 \mathrm{~cm}$. (en el centro y en el extremo); grosor=1$0.6 \mathrm{~cm}$.

(2290) Anchura $=2.1-3.1 \mathrm{~cm}$; grosor $=1-0.5 \mathrm{~cm}$.

(2291) Anchura $=3.4 \mathrm{~cm}$.; grosor $=3.4-1.7 \mathrm{~cm}$.

(2292-2293) Anchura $=1.6 \mathrm{~cm}$.; grosor $=1 \mathrm{~cm}$.

(2294) Anchura $=2.8-4.2 \mathrm{~cm}$; grosor $=1.5-0.6 \mathrm{~cm}$.

(2612) Anchura $=3.4-4 \mathrm{~cm}$.; grosor $=1.4 \mathrm{~cm}$; longitud $=4.4 \mathrm{~cm}$. 


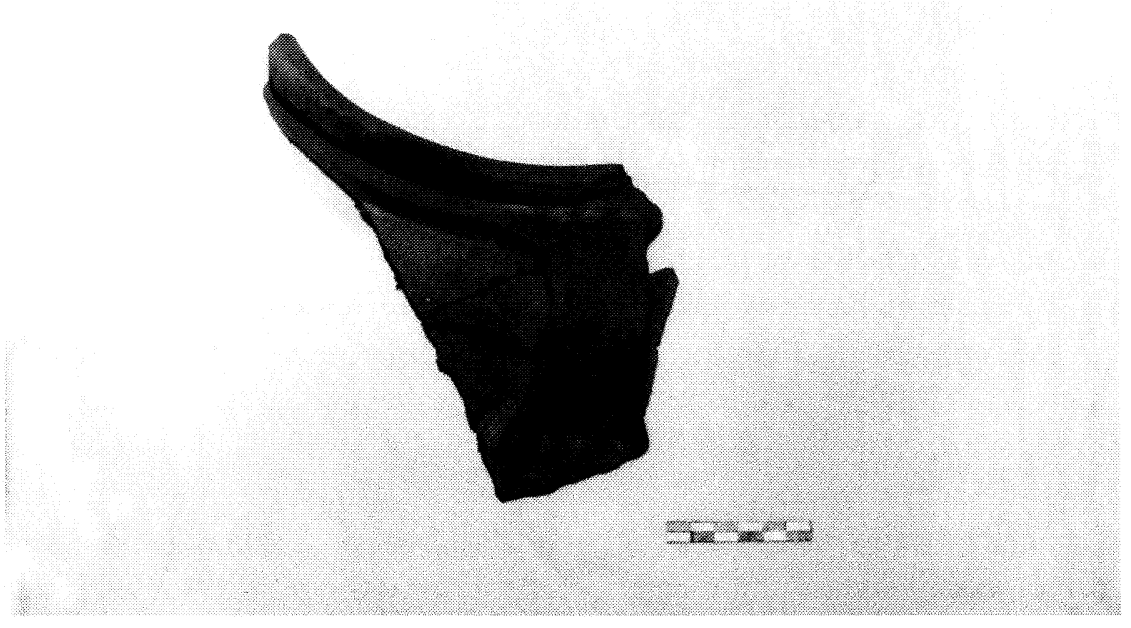

Foto 3.- Pieza 52/170.

\section{4) Amorfos:}

a) Color:

Gris (en diferentes tonalidades, desde el más claro al más oscuro); gris claro en el interior y, hacia la superficie, anaranjado o pardo; gris oscuro en el interior y rojo anaranjado en el exterior; gris oscuro con pigmento castaño claro en la superficie exterior; gris muy claro con parte exterior ocre; gris oscuro con pigmento pardo anaranjado en la superficie exterior; gris oscuro con engobe anaranjado; gris con pigmento negro o gris oscuro en superficie; gris parduzco; gris claro en la mitad interior y anaranjado en la exterior, con pigmento gris en la superficie exterior; gris claro con barniz negro en la superficie exterior y rojo en la interior; gris con pigmento pardo en superficie o pardo anaranjado en la superficie exterior; gris con engobe rojo en el interior y pardo rojizo en el exterior.

Anaranjado; con barniz negro; rojo; la pasta de la pieza 266 es anaranjada con una zona gris, probablemente debida a una carbonización posterior a la fractura de la pieza (esta característica se repite en más piezas); rojo anaranjado; anaranjado en el interior y, hacia la superficie, gris; anaranjado con pigmento gris muy claro en superficie; anaranjado 
con engobe rojo en el exterior (pieza 2194) o interior, o engobe rojo muy oscuro en una de las superficies (piezas 2197, 2225); mitad exterior anaranjado y mitad interior gris, con pigmento gris oscuro; anaranjado con pigmento ocre blanquecino; anaranjado con pigmento gris oscuro en el exterior.

Ocre (diferentes tonos); ocre en el interior y, hacia la superficie, anaranjado; ocre parduzco; con pigmento gris oscuro en el exterior; ocre en la parte interna y gris en la externa; con engobe rojo; con pigmento parduzco en la superficie exterior.

Pardo (del más oscuro al más claro); alguna pieza con barniz negro en superficie; pardo anaranjado; pardo con pigmento anaranjado; con superficie interior negra; pardo con pigmento pardo rojizo en superficie; con pigmento anaranjado en la superficie exterior y negro en la interior; pardo grisáceo; pardo claro con pigmento gris oscuro en superficie; pardo hacia el exterior y gris hacia el interior, con barniz gris oscuro en la superficie exterior; pardo con engobe rojo oscuro en la superficie exterior; pardo rojizo; pardo muy oscuro con barniz negro en superficie.

\section{b) Desgrasantes:}

Graníticos, con abundante mica la mayoría y algunas con muchos cuarzos; de diferentes grosores (gruesos como en las piezas 2463-2536). En alguna pieza (las menos) micáceos, como la 2452.

\section{c) Terminación:}

Bruñida, a veces espatulada, en la superficie exterior y espatulada o afinada en la interior; en alguna pieza, escobillado en la superficie interior; grosera; afinada; barnizada; barniz en la superficie exterior y grosera en la interior; las piezas 261, 2629-2630 están afinadas en la superficie exterior y vidriadas en la interior; bruñida y, a veces, pigmentada; afinada y engobada; espatulada; afinada en el exterior y pigmentada en el interior; barnizada y bruñida en el exterior y grosera en la interior; pigmentada y espatulada; afinada en la superficie exterior, escobillada en la interior y pigmentada en toda la superficie; bruñida y espatulada; escobillada.

d) Cocción:

Reductora, oxidante (en porcentajes similares); reductora primero y, después, oxidante (y viceversa); alguna pieza presenta una cocción irre- 
gular: gris oscuro y, en partes del interior, anaranjado; oxidante y reductora en una misma pieza.

\section{e) Decoración:}

Líneas horizontales incisas (algunas con líneas oblícuas puntilladas en el medio); líneas horizontales excisas; arcos de medio punto puntillados; líneas oblícuas o verticales incisas; líneas horizontales o verticales bruñidas; bandas horizontales incisas y columnas de «strígiles», como en la pieza 93, decoración muy abundante en el ámbito castreño ( ver foto 4). Se repite en más piezas. Molduras horizontales excisas; en la pieza 153, impresión de cestería o estampillado; esgrafiado; banda horizontal incisa y, debajo, líneas oblícuas incisas (característico de las primeras etapas de época romana, según E. Alcorta Irastorza); en la pieza 290 dos bandas horizontales incisas acanaladas y, en la parte superior, decoración estampillada de friso de arcos de medio punto unidos por sus diámetros (al igual que la pieza 2255), realizada mediante pequeños puntos cuadrangulares. Según E. Alcorta, este tipo de decoración es característica de la cerámica indígena de una primera época romana.

Puntos estampillados; decoración de retícula bruñida, acompañada o no de una línea horizontal incisa o bruñida; dos líneas horizontales bruñidas y, en el medio, una moldura horizontal excisa; líneas oblícuas bruñidas cortadas en parte por otras tres líneas oblícuas, paralelas entre sí, más finas y juntas que las anteriores; dos bandas horizontales incisas acanaladas; en el medio, líneas verticales incisas; bandas horizontales, oblícuas o verticales bruñidas no uniformes; en la pieza 544, decoración puntillada en forma de $\langle\mathrm{V}\rangle$; en la pieza 559 , tres molduras horizontales excisas en la parte superior de la pieza y, en la inferior, tres círculos concéntricos estampillados; inscripción esgrafiada (pieza 2080); dos bandas horizontales incisas acanaladas y, en el medio, líneas dobles en zig-zag incisas; línea ondulada incisa; líneas oblícuas bruñidas junto a líneas discontínuas incisas; líneas horizontales incisas acanaladas y, entre ellas, líneas oblícuas puntilladas (con una especie de ruedecilla); columnas de «strígiles» separadas por líneas horizontales.

La pieza 2583 presenta tres zonas decoradas a modo de cenefas, separadas por zonas lisas: la primera con impresiones hechas con una ruedecilla u otro instrumento similar, la segunda con «strígiles» triples impresos, la tercera con «strígiles» sencillos impresos. Cada zona enmarcada por 


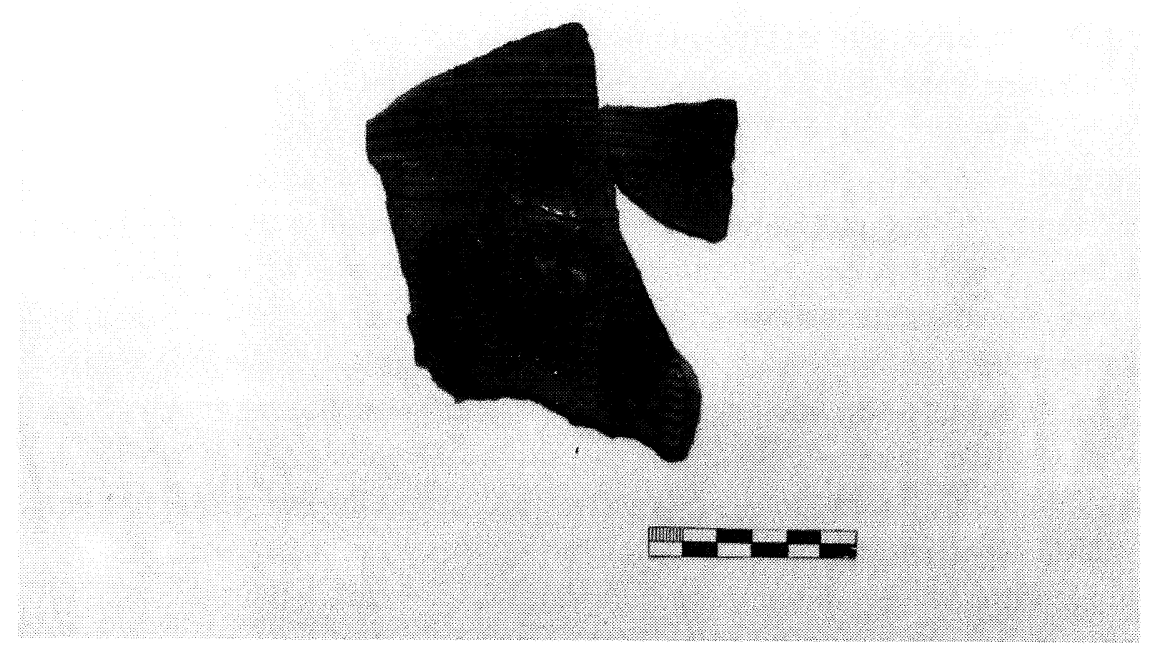

Foto 4.- Pieza 93.

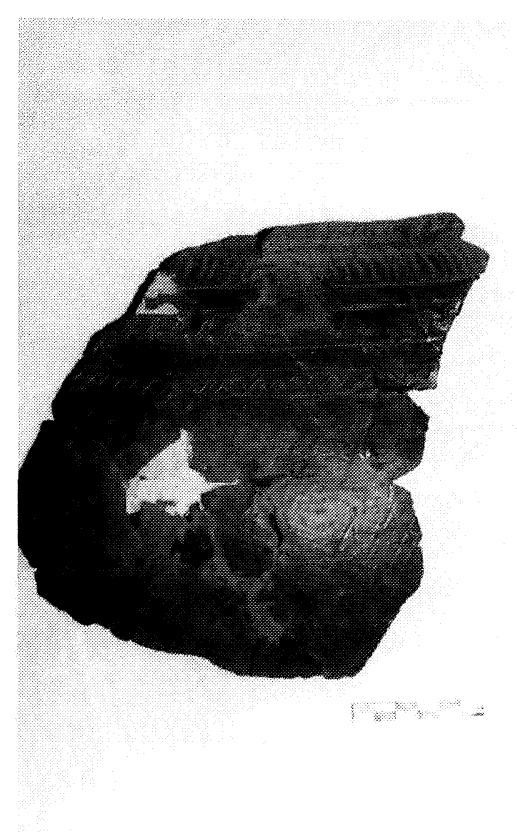

Foto 5.- Pieza 2583. 
dos líneas horizontales incisas. Debajo, decoración de retícula bruñida; mamelones y, debajo, moldura horizontal excisa con líneas horizontales impresas (ver foto 5 ).

La decoración sigue siendo la de la etapa anterior a la romanización, en su mayor parte.

\section{f) Observaciones:}

La mayoría con ennegrecimiento por su exposición al fuego como recipientes para cocción. Hay piezas que sólo presentan carbonización en su superficie interior y otras ennegrecimiento por carbonización posterior a su fractura.

Algunas piezas presentan perfil curvo convexo (cuencos); muchas son de gran tamaño y paredes gruesas (las piezas 247 y 356 podrían ser barreños, recipientes utilizados para lavar), otras como las 137 y 442 tienen paredes muy finas; algunas muestran, en su parte interior, molduras horizontales excisas que pudieran servir para asentar una tapadera; la 2583 también es de gran tamaño (puede tratarse de un recipiente de almacenaje); la pieza 176 posiblemente se trate de cerámica de mesa a juzgar por su acabado y finas paredes.

Aparece cerámica a torno como las piezas 535, 2115, 2117-2119, 21242125 y otras (utilización de técnica romana); a torno lento o torneta como las 2122 y 2131 ; cerámica de fundición (pieza 548) con resto muy pequeño de escoria que presenta oxidación y señales de exposición al fuego.

\section{5) Terra sigillata:}

a) Tipo:

Terra sigillata con marca de fábrica (ilegible a partir del fragmento conservado); terra sigillata hispánica decorada, forma Dragendorff 29 (pieza 84): (ver foto 6) especie de cuenco con carena, borde oblícuo y labio redondeado; base oblícua abierta de fondo plano y reborde perimetral curvo cóncavo (pieza 86/89); borde horizontal y labio redondeado (pared muy fina) (pieza 371-372); base de terra sigillata hispánica, forma Dragendorff 15/17, de fondo curvo cóncavo y reborde perimetral curvo convexo (pieza 2078); borde de terra sigillata gálica decorada, forma Dragendorff $24 / 25$, con labio redondeado y moldura horizontal excisa (pieza 2079); base de terra sigillata; borde de labio oblícuo; fragmentos y astillas.

"CUADERNOS DE ESTUDIOS GALLEGOS", Tomo XLVII, Fascículo 112, Santiago 2000. 
Terra sigillata gálica decorada, forma Dechel 68 (pieza 2134); bases de pared oblícua y fondo ligeramente curvo cóncavo, con reborde perimetral curvo convexo (piezas 2135-2136); borde obícuo abierto con labio apuntado (pieza 2137); labio apuntado (pieza 2138); labio redondeado (piezas 2139-2140); amorfos.

Terra sigillata hispánica decorada, forma Dragendorff 24/25 (pieza 2143, g); terra sigillata decorada (pieza 2144, p); terra sigillata hispánica, forma Dragendorff $15 / 17$, base de pared oblícua abierta y fondo curvo cóncavo con reborde perimetral curvo convexo (pieza 2145, c); terra sigillata gálica, base de fondo plano con pie vertical que presenta una pequeña inflexión en el centro (pieza 2146, d); base de pared curvo convexa y fondo plano, con reborde perimetral curvo convexo (pieza 2147,f); borde recto con labio semicircular; (pieza 2149, h) borde recto vertical con labio semicircular (pieza 2148, y); borde oblícuo abierto con labio redondeado y engrosado hacia el exterior (pieza $2150, \mathrm{j}$ ); borde con labio redondeado engrosado hacia el exterior (pieza 2151, 1); borde con labio ligeramente oblícuo (pieza 2152, k); borde con labio semicircular (pieza 2153,e); terra sigillata hispánica, forma Dragendorff 37, borde con labio redondeado (pieza 2154, a); borde con labio redondeado engrosado hacia el exterior (pieza 2155, m); terra sigillata gálica, forma Dragendorff 27, borde curvo cóncavo con labio redondeado (pieza 2156,b); amorfos; fragmentos de terra sigillata hispánica decorada (piezas 2168-2172); borde curvo convexo con labio redondeado; base de fondo curvo cóncavo con reborde perimetral curvo convexo; borde con labio apuntado.

\section{b) Color:}

Pardo claro con acabado rojo oscuro brillante (pieza 84); anaranjado claro con acabado rojo oscuro brillante (pieza 86/89); rojo anaranjado claro; rojo oscuro (piezas 2078-2079); rojo claro con acabado rojo más oscuro (piezas 2134-2172); rojo muy claro con acabado rojo oscuro brillante; rojo muy claro (piezas 2600-2606); anaranjado (pieza 2607).

c) Desgrasantes:

Graníticos o micáceos apenas visibles en algunas piezas y, en otras, no se perciben. 
d) Terminación:

Pigmentada y muy brillante en la mayoría; afinada.

e) Cocción:

Oxidante.

f) Decoración:

La pieza 84 presenta motivos decorativos estampillados de pequeño formato, humanos, separados por metopas, superpuestos en varios frisos divididos por una doble moldura horizontal excisa muy fina. Decoración de ángulos entre metopas. Según E. Alcorta Irastorza, se inspira en motivos del Alto Imperio. Hacia finales del siglo Id.C. se hace normal la decoración en metopas.

En la pieza 2079, línea horizontal incisa y decoración estampillada de líneas verticales; decoración vegetal inscrita en un círculo (pieza 2134); en la pieza 2144 no se puede apreciar el tipo de modelo decorativo debido a su mal estado de conservación; motivos vegetales inscritos en círculos (piezas 2168-2172).

g) Observaciones:

En general, mal estado de conservación.

\section{6) Lucernas:}

a) Tipo:

La pieza 2071 es una lucerna de «canal abierto», también denominadas «lucernas de fábrica». Son de factura menos cuidada que los restantes tipos. Presenta pie circular y agujero de alimentación en la mitad inferior del «discus». Pico redondeado (ver foto 7).

La pieza 2072 es una lucerna «de volutas» de pico triangular. Es de factura más cuidada. Pie plano y circular marcado por una incisión. Agujero de alimentación en la mitad inferior del «discus» (ver foto 8).

Fragmento de orla de lucerna de volutas (pieza 2073); piquera de lucerna de volutas (pieza 2074); voluta fragmentada (pieza 2075); fragmentos de lucernas (pieza 2076-2077); fragmento de lucerna, parece de volutas (2084). 


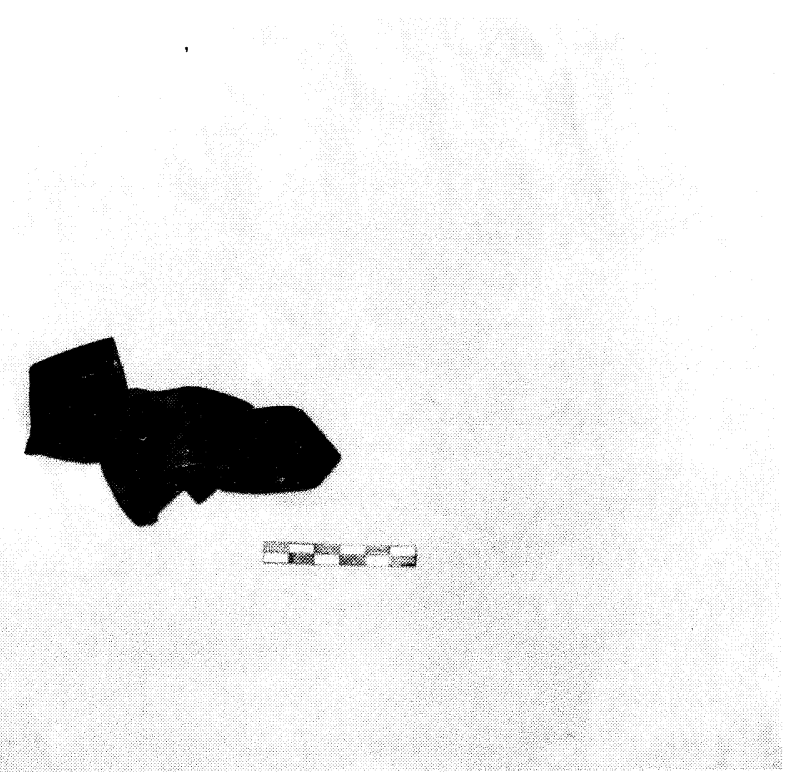

Foto 6.- Pieza 84.

\section{b) Color:}

Anaranjado (pieza 2071); ocre con engobe castaño oscuro (2072); amarillenta con engobe castaño oscuro y reflejo metálico (2073); anaranjado claro con engobe castaño (2074); anaranjado claro (2075); pardo grisáceo claro con engobe gris oscuro (2076); anaranjado claro con engobe gris oscuro (2077); anaranjado (2084).

c) Desgrasantes:

Todos graníticos apenas visibles, excepto en la pieza 2075, que son micáceos.

\section{d) Terminación:}

Las piezas 2071, 2075, afinadas; 2072, 2073, 2076 y 2077, bruñidas; la 2084 afinada (en algunas zonas parece espatulada), y quizás engobada.

e) Cocción:

Oxidante, excepto en la 2076, reductora.

"CUADERNOS DE ESTUDIOS GALLEGOS", Tomo XLVII, Fascículo 112, Santiago 2000. 


\section{f) Decoración:}

(Pieza 2071): Este tipo de lucernas apenas presenta decoración: moldura excisa bordeando la «orla o margo» de la que salen tres pequeñas molduras excisas. Ésta continúa bordeando el pico o «mixus».

(Pieza 2072): Dos líneas incisas bordeando la «orla o margo». En el «discus», decoración estampillada que representa, según Fariña Busto, un tema animalístico (ave volando hacia la izquierda); en la pieza 2073, línea incisa bordeando la orla y, en el disco, representación del busto de Helios; en la pieza 2074, tres líneas incisas bordeando la orla.

\section{g) Medidas:}

(Pieza 2071) Diámetro $=4.3 \mathrm{~cm} . ;$ longitud $=7.2 \mathrm{~cm} . ;($ pieza 2072) diámetro $=4.5 \mathrm{~cm}$.; longitud $=7.4 \mathrm{~cm}$.

\section{h) Conservación y observaciones:}

En general mala ( la pieza 2072 está fragmentada y gran parte del engobe de la superficie desprendido; la 2074 está muy rodada), excepto la pieza 2071.

(Pieza 2071): Según J. Naveiro, su cronología comprendería desde la segunda mitad del siglo Id.C. hasta principios del siglo IIId.C.

(Pieza 2072): Este tipo de lucernas presenta menor difusión que las de pico redondeado. Apareció en un nivel de incendio y relleno, asociada a material de la misma época.Entre las lucernas de volutas hay piezas, según J. Naveiro, de indudable importación itálica. Ésta correspondería al tipo II B1 de Ponsich (segunda mitad del siglo Id.C.), según Fariña Busto.

\section{7) Otros materiales:}

- Material constructivo: fragmentos de «tegula».

- «Fusaiolas»: una de color pardo y otra gris oscuro. Los desgrasantes son graníticos con abundante mica, la terminación afinada y la cocción oxidante, en una, y reductora, en otra.

Medidas: diámetro total $=4.1$ y $3.6 \mathrm{~cm}$.; diámetro del orificio central $=$ 1 y $0.5 \mathrm{~cm}$.; grosor $=0.6 \mathrm{~cm}$. las dos (las medidas de la segunda pieza son aproximadas debido a su mal estado de conservación). Ambas presentan señales de exposición al fuego. 


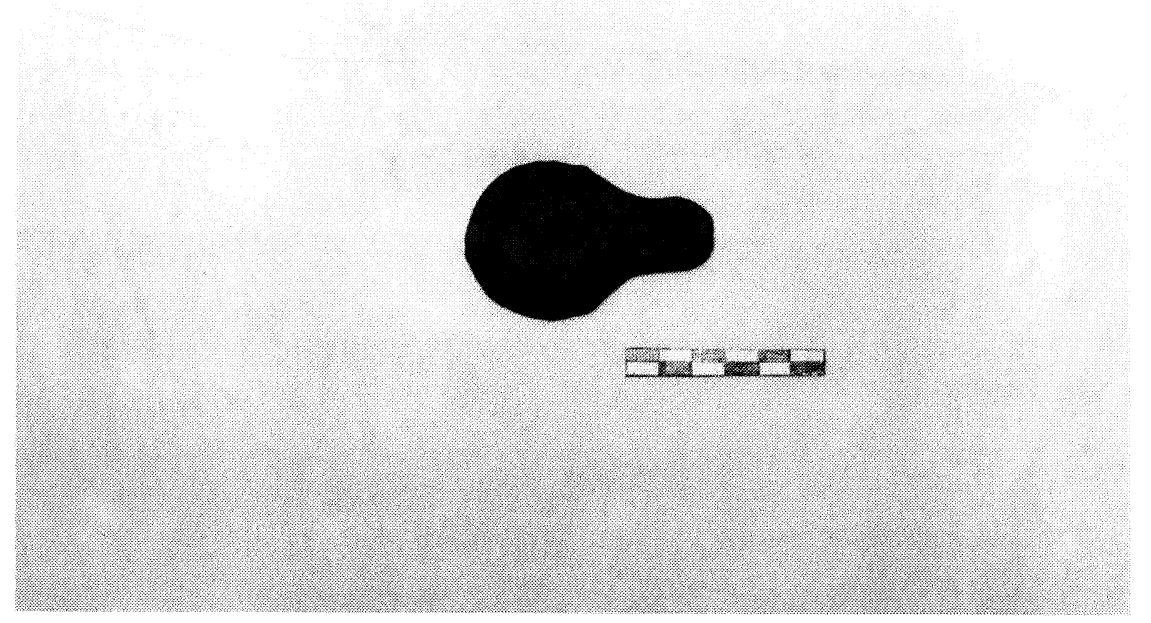

Foto 7.- Pieza 2071.

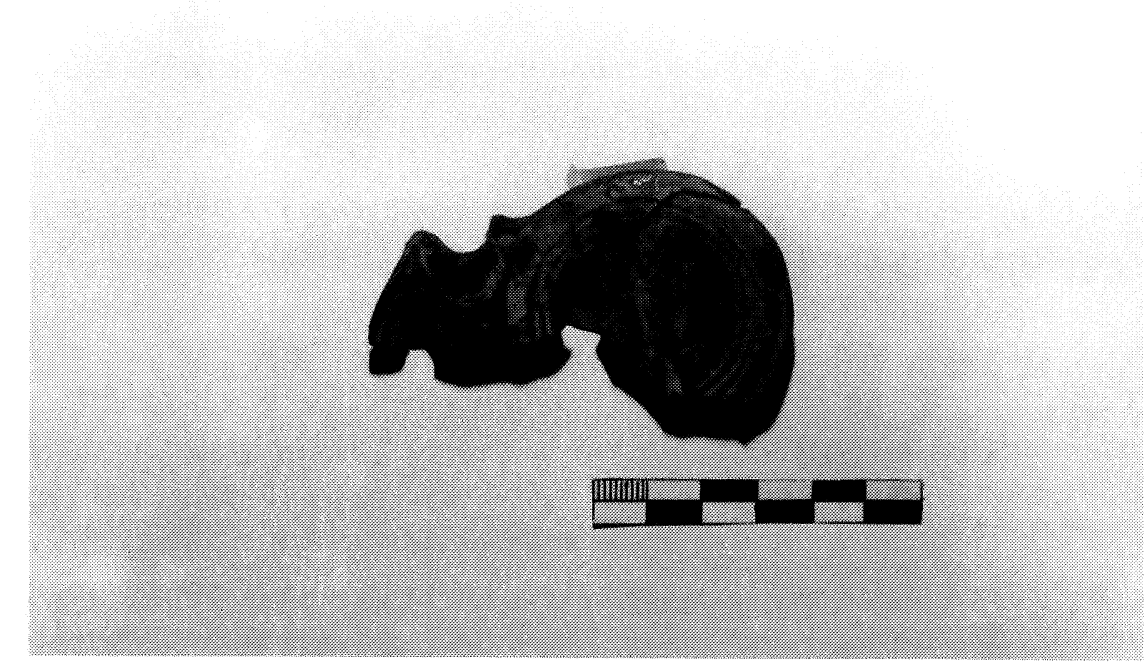

Foto 8.- Pieza 2071. 


\section{BIBLIOGRAFÍA}

ALCORTA IRASTORZA, E.: Avance al estudio de la cerámica común romana de cocina y mesa de Lucus Augusti, «Cerámica comuna romana de época alto-imperial a la Península Ibérica. Estat de la qüestió», Monografies Emporitanes VIII, Empúries, 1994, 201-226.

BELTRÁN, M.: Guía de la cerámica romana, Zaragoza, 1990, 89-120.

CAAMAÑO GESTO, J.M.: As vías romanas, Santiago de Compostela, 1984, 17-31.

FARIÑA BUSTO, F.: Lucernas romanas de los museos de Orense y Pontevedra, Boletín Auriense, vol. 6, Orense, 1976, 131-148.

GONZÁLEZ ALÉN, D.: «Fafián», Gran Enciclopedia Gallega, vol. 11, Santiago de Compostela, 1974, 69.

LÓPEZ CUEVILLAS, F.: La civilización céltica en Galicia, Madrid, 1989.

LLANOS: Ensayo metodológico para el estudio de la cerámica.

NAVEIRO LÒPEZ, J.L.: El comercio antiguo en el noroeste peninsular, La Coruña, 1991, 50-55.

Yacimiento de "Porta de Arcos» (Rodeiro, Pontevedra). Villa romana, Museo de Pontevedra, vol. 27, Pontevedra, 1973, 65-68.

"CUADERNOS DE ESTUdIOS GALLEGOS", Tomo XLVII, Fascículo 112, Santiago 2000. 